\title{
Development and Validation of a Novel Vancomycin Dosing Nomogram for Achieving High-Target Trough Levels at 2 Canadian Teaching Hospitals
}

\author{
Rosanne Thalakada, Michael Legal, Tim T Y Lau, Tiffany Luey, Josh Batterink, and Mary H H Ensom
}

\begin{abstract}
Background: Recent guidelines recommend a vancomycin trough (predose) level between 15 and $20 \mathrm{mg} / \mathrm{L}$ in the treatment of invasive gram-positive infections, but most initial dosing nomograms are designed to achieve lower targets $(5-15 \mathrm{mg} / \mathrm{L})$. Clinicians need guidance about appropriate initial dosing to achieve the higher target.

Objective: To develop and validate a high-target vancomycin dosing nomogram to achieve trough levels of $15-20 \mathrm{mg} / \mathrm{L}$.

Methods: A retrospective study was conducted at 2 teaching hospitals, St Paul's Hospital and Vancouver General Hospital in Vancouver, British Columbia. Patients who were treated with vancomycin between January 2008 and June 2010 and who had achieved a trough level of 14.5-20.5 $\mathrm{mg} / \mathrm{L}$ were identified. Demographic and clinical data were collected. Multiple linear regression was used to develop a vancomycin dosing nomogram for each hospital site. An integrated nomogram was constructed by merging the data from the 2 hospitals. A unique set of patients at each institution was used for validating their respective nomograms and a pooled group of patients for validating the integrated nomogram. Predictive success was evaluated, and a nomogram was deemed significantly different from another nomogram if $p<0.05$ via " $\chi^{2}$ testing.
\end{abstract}

Results: Data from 78 patients at one hospital and 91 patients at the other were used in developing the respective institutional nomograms. For each hospital's data set, both age and initial serum creatinine were significantly associated with the predicted dosing interval $(p<0.001)$. Validation in a total of 105 test patients showed that the integrated nomogram had a predictive success rate of $56 \%$.

Conclusions: A novel vancomycin dosing nomogram was developed and validated at 2 Canadian teaching hospitals. This integrated nomogram is a tool that clinicians can use in selecting appropriate initial vancomycin regimens on the basis of age and serum creatinine, to achieve high-target levels of $15-20 \mathrm{mg} / \mathrm{L}$. The nomogram should not replace clinical judgment for patients with unstable and/or reduced renal function.

Key words: vancomycin, therapeutic drug monitoring, nomograms

Can J Hosp Pharm 2012;65(3):180-187

\section{RÉSUMÉ}

Contexte : Des lignes directrices récentes recommandent des concentrations minimales (prédose) entre 15 et $20 \mathrm{mg} / \mathrm{L}$ pour le traitement des infections envahissantes à bactéries Gram-positif, mais la plupart des nomogrammes pour la posologie initiale sont conçus pour obtenir des concentrations cibles plus faibles (entre 5 et $15 \mathrm{mg} / \mathrm{L}$ ). Les cliniciens ont besoin de conseils pour établir la posologie initiale appropriée permettant d'atteindre des concentrations cibles plus élevées.

Objectif : Développer et valider un nomogramme posologique ciblant des concentrations minimales élevées entre 15 et $20 \mathrm{mg} / \mathrm{L}$.

Méthodes : Une étude rétrospective a été menée dans deux hôpitaux universitaires de Vancouver (Colombie-Britannique), l'Hôpital St. Paul et l'Hôpital général de Vancouver. Les patients traités par la vancomycine entre janvier 2008 et juin 2010 chez qui on a obtenu des concentrations minimales se situant entre 14,5 et $20,5 \mathrm{mg} / \mathrm{L}$ ont été recensés. Les données démographiques et cliniques ont été collectées. Une analyse de régression linéaire multiple a servi à développer un nomogramme posologique pour la vancomycine à chaque hôpital. Un nomogramme intégré a été construit en fusionnant les données des deux hôpitaux. Une série unique de patients à chaque hôpital a servi à valider leur nomogramme respectif; un groupe combiné de patients, le nomogramme intégré. La réussite prévisionnelle a été évaluée et un nomogramme était jugé comme étant significativement différent d'un autre si $p<0,05$ d'après le test du chi carré.

Résultats : Les données de 78 patients dans l'un des hôpitaux et de 91 patients dans l'autre ont été utilisées pour développer leurs nomogrammes respectifs. Pour l'ensemble de données de chaque hôpital, l'âge et la créatininémie étaient tous deux des variables prédictives significatives de l'intervalle posologique $(p<0,001)$. La validation chez un total de 105 patients expérimentaux a montré que le nomogramme intégré avait un taux de réussite prévisionnel de $56 \%$.

Conclusions : Un nomogramme posologique novateur pour la vancomycine a été développé et validé dans deux hôpitaux universitaires canadiens. Ce nomogramme intégré aidera les cliniciens à choisir les posologies initiales de vancomycine en tenant compte de l'âge et de la créatininémie, afin d'atteindre les concentrations cibles élevées de 15 à 20 $\mathrm{mg} / \mathrm{L}$. Le nomogramme ne doit pas remplacer le jugement du clinicien chez les patients dont la fonction rénale est instable ou réduite.

Mots clés : vancomycine, suivi thérapeutique pharmacologique, nomogrammes

[Traduction par l'éditeur] 


\section{INTRODUCTION}

$\mathrm{V}$ ancomycin is a glycopeptide antibiotic that exerts concentration-independent killing of gram-positive cocci. ${ }^{1-3}$ It is considered bactericidal against Staphylococcus and Streptococcus and bacteriostatic against Enterococcus. After more than 50 years of clinical use, vancomycin remains one of the most widely used antibiotics against staphylococci (including methicillin-resistant Staphylococcus aureus [MRSA]), streptococci, and enterococci for the treatment of abscesses, osteomyelitis, endocarditis, meningitis, bacteremia, and other infections. It is one of the most extensively studied antibiotics in terms of its pharmacokinetic and pharmacodynamic properties in a variety of patient populations. There is substantial interpatient variability in response to the drug, according to the individual's age, renal function, and concomitant disease states. ${ }^{4}$ Given that a correlation between creatinine clearance and vancomycin clearance has been clearly demonstrated, ${ }^{5}$ dosage adjustments based on renal function are warranted.

Peak vancomycin concentration is no longer used as a clinical indicator. It is an unreliable marker because of the multi-exponential decline in the curve relating vancomycin concentration to time, and the slow distribution of vancomycin to the peripheral tissues makes it difficult to determine the true peak. ${ }^{6}$ The ratio of the area under the curve (AUC) to the minimum inhibitory concentration (MIC) has been shown to be a valuable pharmacodynamic parameter that has been correlated with vancomycin efficacy in in vitro, in vivo, and limited clinical studies. ${ }^{7}$ However, it is difficult and impractical to measure serum vancomycin concentration multiple times to determine the AUC clinically. Trough concentrations have been shown to significantly correlate with $\mathrm{AUC}^{8}$ and may therefore be used as a marker of efficacy.

The optimal target for serum vancomycin trough concentration is controversial. The most recent guidelines for vancomycin therapy, ${ }^{6}$ based on a consensus review, recommended that trough levels be consistently maintained above $10 \mathrm{mg} / \mathrm{L}$, and for pathogens with an MIC of at least $1 \mathrm{mg} / \mathrm{L}$, serum concentrations above $15 \mathrm{mg} / \mathrm{L}$ were recommended. Moise-Broder and others ${ }^{9}$ found that an AUC:MIC ratio of 345:1 was necessary for a successful clinical outcome in treating ventilator-associated $S$. aureus pneumonia. Therefore, an AUC:MIC ratio of at least 400:1 was recommended in these recent guidelines. ${ }^{6}$ Furthermore, maintaining a higher trough concentration $(15-20 \mathrm{mg} / \mathrm{L})$ could potentially improve tissue penetration and clinical outcomes for complicated infections.

The most recent guidelines also recommended that trough concentrations be monitored in certain patients, ${ }^{6}$ including those who undergo prolonged therapy (longer than 3-5 days), those who require target trough concentrations above $15 \mathrm{mg} / \mathrm{L}$, those who are receiving nephrotoxins, and those with unstable renal function.
Until the time of the study reported here, St Paul's Hospital and Vancouver General Hospital (both in Vancouver, British Columbia) had institutional dosing guidelines aimed at achieving a trough vancomycin level of $5-15 \mathrm{mg} / \mathrm{L}$. Without initial dosing guidelines to direct high-target prescribing, clinicians were using empiric dosing strategies in their attempts to achieve higher trough concentrations, but the results were variable. This approach is not ideal, but at the time this study was initiated, there were no validated dosing nomograms in the literature to better guide practice. As such, a need to develop nomograms to better direct vancomycin dosing strategies was identified. The primary objective of this study was to develop and validate initial vancomycin dosing nomograms to target trough concentrations of $15-20 \mathrm{mg} / \mathrm{L}$ in adult patients at the 2 study hospitals. A secondary objective was to compare the predictability of candidate nomograms and, if possible, to identify the best single nomogram for use at both sites.

\section{METHODS}

\section{Study Design}

This retrospective, multicentre study was conducted at St Paul's Hospital and Vancouver General Hospital. Both are tertiary care teaching hospitals located in an urban setting. St Paul's Hospital serves an inner-city patient population, including a large cohort of injection drug users. Vancouver General Hospital cares for a diverse patient population and provides some additional specialty services for trauma and burns.

\section{Participants}

Patients were included if they were 19 years of age or older; had an infection; required IV vancomycin treatment; and had an indication for trough levels of $15-20 \mathrm{mg} / \mathrm{L}$, where such indications included but were not limited to meningitis, endocarditis, pneumonia, bacteremia, sepsis, and osteomyelitis. The indications were confirmed by examining documentation in the patients' health records. Patients must have had at least one reported determination of serum creatinine upon initiation of the vancomycin regimen. Furthermore, patients must have had at least one steady-state trough level of $14.5-20.5 \mathrm{mg} / \mathrm{L}$ for a sample drawn within 10 days after initiation of vancomycin. For the purposes of inclusion, the range $14.5-20.5 \mathrm{mg} / \mathrm{L}$ was chosen as a surrogate for the therapeutic range of $15-20 \mathrm{mg} / \mathrm{L}$, because clinicians at the 2 sites typically consider levels within $0.5 \mathrm{mg} / \mathrm{L}$ of either end of the range as being therapeutic.

Patients were excluded if they were in acute or chronic renal failure with creatinine clearance (as estimated by the Cockcroft-Gault equation) of less than $10 \mathrm{~mL} / \mathrm{min}$, were undergoing hemodialysis, or had not had a steady-state vancomycin trough level recorded. Patients from the following clinical areas were also excluded: palliative care, psychiatry, emergency medicine, and tuberculosis care. 
Patients who met the inclusion criteria and were not excluded by the exclusion criteria were randomly assigned (by means of a random sequence generator) to either nomogram development or nomogram validation.

The overall sample size for the study was based on the number of patients who were admitted to either institution between January 2008 and June 2010 and who met the criteria for inclusion.

\section{Data Collection}

Upon approval from the University of British Columbia Providence Health Care Research Ethics Board and the Vancouver Coastal Health Research Institute, patients from each site who had achieved vancomycin trough levels between 14.5 and $20.5 \mathrm{mg} / \mathrm{L}$ in the period January 2008 to June 2010 were identified using a cross-site laboratory database.

From the health care record, various demographic data, including age, sex, and actual body weight, were collected. The initial vancomycin dosing regimen (dose and frequency) was also gathered, along with clinical information, specifically comorbidities (categorized by organ system), primary diagnosis, infectious diagnosis, and pathogens. The medication administration records were reviewed to determine whether all doses had been given on time. If the doses were administered on schedule and the sample for determining vancomycin level had been drawn at the appropriate time, the level was considered to be at steady state. The patients' progress notes were reviewed for any clinical information relating to vancomycin therapy.

From the laboratory information system, each patient's initial serum creatinine, changes in serum creatinine, and vancomycin trough levels were collected. The medical service unit to which the patient had been admitted was also noted.

\section{Nomogram Development}

Once data collection was complete, 2 institution-specific dosing nomograms were developed. For each nomogram, multiple linear regression via Minitab 15 statistical software (Minitab Inc, State College, Pennsylvania) was used to predict dosing intervals, with age, initial serum creatinine, and actual body weight as variables. The data sets were also combined to produce a third, integrated nomogram, which was intended as a more robust nomogram that could be applied at both sites. The 3 variables (age, initial serum creatinine, and actual body weight) were chosen because vancomycin clearance and creatinine clearance have been shown to be significantly associated. ${ }^{10,11}$ However, initial serum creatinine level, rather than creatinine clearance, was chosen to make it easy for prescribers to use the nomogram without having to calculate the creatinine clearance. In addition, although estimated glomerular filtration rate is routinely reported, there are no good data correlating this measure with vancomycin clearance.
Furthermore, preliminary calculations suggested that the estimated glomerular filtration rate may not, in fact, correlate well with vancomycin clearance across all age ranges.

For each age and serum creatinine category, the midpoint was used in the regression equation to predict dosing intervals. For example, for the categories for age group 20-29 years and initial serum creatinine $40-60 \mu \mathrm{mol} / \mathrm{L}$, the values used in the equation were 25 years and $50 \mu \mathrm{mol} / \mathrm{L}$, respectively. The absolute dosing intervals were then rounded to standard dosing intervals for vancomycin $(8,12,18,24,36$, and $48 \mathrm{~h})$ and used to construct the nomogram.

\section{Nomogram Validation}

The nomograms were validated using the second group of patients identified during the initial randomization. None of the patients whose data were used for nomogram development were included in this validation group, to ensure that the validation cohort was truly independent.

Validation of each institution's nomogram was achieved by calculating the proportion of unique patients for whom the nomogram correctly predicted the appropriate dosing interval to attain a steady-state trough vancomycin level of $15-20 \mathrm{mg} / \mathrm{L}$.

Each nomogram was validated with patients from the corresponding hospital site and was also cross-validated with patients from the other hospital site. The integrated nomogram was validated with a larger pool of patients from both sites.

\section{Statistical Comparison of Nomograms}

The proportions of unique patients in each test group for whom the St Paul's Hospital nomogram, the Vancouver General Hospital nomogram, and the integrated nomogram predicted the appropriate dosing intervals were compared with a $\chi^{2}$ test (with a priori definition of $p<0.05$ as significant). In addition, for each nomogram, predictive success including the $\mathrm{q} 18 \mathrm{~h}$ dosing interval was compared with predictive success excluding the $\mathrm{q} 18 \mathrm{~h}$ dosing interval using the $\chi^{2}$ test (with a priori definition of $p<0.05$ as significant). No comparisons were made between the site and integrated nomograms excluding the $\mathrm{q} 18 \mathrm{~h}$ dosing interval.

\section{RESULTS}

\section{Participants}

The health care records of 320 patients treated at St Paul's Hospital or Vancouver General Hospital between January 2008 and June 2010 were reviewed for screening against the inclusion and exclusion criteria.

For development of the nomograms, 78 patients were included in the St Paul's Hospital group and 91 in the Vancouver 
General Hospital group. For validation of the nomograms, a total of 105 patients were included. This number comprised 44 patients from St Paul's Hospital and 36 patients from Vancouver General Hospital used to validate the site-specific nomograms and an additional 25 patients (11 from St Paul's Hospital and 14 from Vancouver General Hospital) to create a larger pooled sample for validation of the integrated nomo- gram. Reasons for exclusion were renal failure, longer than 10 days to reach target steady-state level, absence of steady-state levels, and stated target trough levels below $15 \mathrm{mg} / \mathrm{L}$.

\section{Demographic and Clinical Characteristics}

Of the patients used for nomogram development, the group at St Paul's Hospital had a higher proportion of men,

\section{Table 1. Demographic and Clinical Characteristics of Patients Whose Data Were Used in Development of a Dosing Nomogram}

\begin{tabular}{lcc} 
Characteristic & $\begin{array}{c}\text { St Paul's Hospital } \\
(\boldsymbol{n}=\mathbf{7 8})\end{array}$ & $\begin{array}{c}\text { Vancouver General Hospital } \\
(\boldsymbol{n}=\mathbf{9 1})\end{array}$ \\
\hline Age (years), median (IQR) and range & $55(28)[28-87]$ & $58(31)[20-89]$ \\
Sex, no. $(\%)$ male & $58(74)$ & $52(57)$ \\
Weight (kg), mean \pm SD & $78 \pm 18$ & $70 \pm 18$ \\
Initial serum creatinine ( $\mu$ mol/L), & $74(58)[42-180]$ & $86(35)[43-175]$ \\
$\quad$ median (IQR) and range & & \\
Vancomycin level (mg/L), median (IQR) & $17.6(2.9)$ & $17.1(2.8)$ \\
Vancomycin dose (mg/kg), mean \pm SD & $15 \pm 4$ & $16 \pm 3$ \\
Most common causative organism & MRSA & MRSA
\end{tabular}

$\mathrm{IQR}=$ interquartile range, MRSA = methicillin-resistant Staphylococcus aureus,

$\mathrm{SD}=$ standard deviation

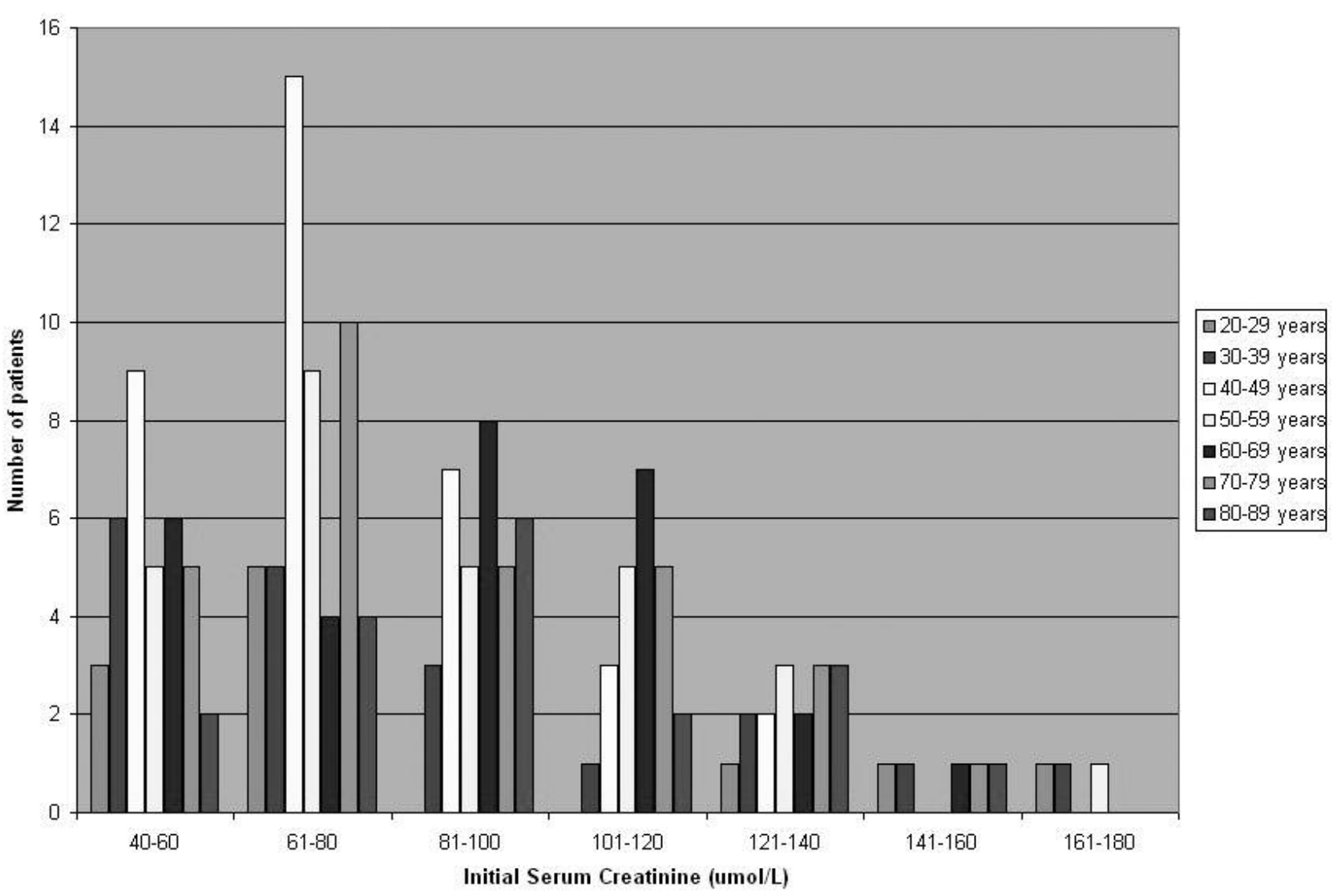

Figure 1. Number of patients in each serum creatinine and age category used for nomogram development. 


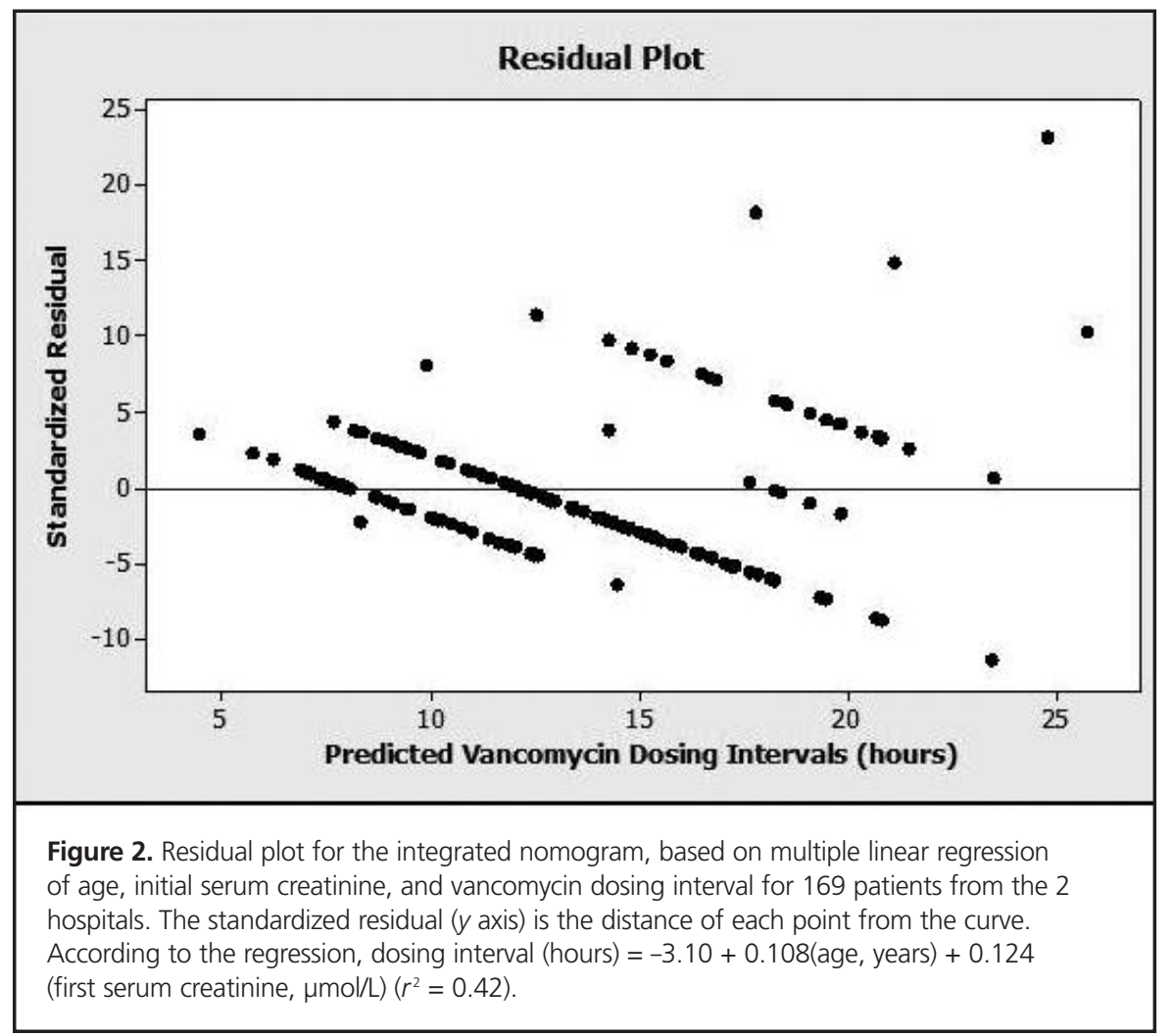

patients were heavier, and the median initial serum creatinine level was lower. The groups were similar in terms of other demographic and clinical characteristics (Table 1). For the nomogram relating age and initial serum creatinine (Figure 1), most patients fell in the central categories: between 30 and 79 years of age with initial serum creatinine values between 40 and $120 \mu \mathrm{mol} / \mathrm{L}$.

\section{Nomogram Development}

For each hospital's data set, both age and first serum creatinine were significantly associated with the predicted dosing interval $(p<0.001)$. Actual body weight was not significantly associated with the predicted dosing interval and was therefore omitted from the regression equation. It took, on average, 4 days to achieve target trough levels.

\section{Institution-Specific Nomograms}

Multiple regression analysis of the institution-specific data yielded the following equations:

St Paul's Hospital: Dosing interval (hours) $=-1.074+$ 0.088 (age, years) +0.129 (first serum creatinine level, $\mu \mathrm{mol} / \mathrm{L}$ ) Vancouver General Hospital: Dosing interval (hours) $=-1.076+$ 0.172(age, years) +0.043 (first serum creatinine level, $\mu \mathrm{mol} / \mathrm{L}$ )

\section{Integrated Nomogram}

Multiple linear regression analysis of the integrated data from both hospitals yielded the following equation: Dosing interval (hours) $=-3.10+0.108$ (age, years) + 0.124 (first serum creatinine level, $\mu \mathrm{mol} / \mathrm{L}$ )

The residual plot for the integrated nomogram (Figure 2) represents the difference between the observed response and the value predicted by the regression line. The points in the residual plot are randomly distributed above and below the curve. Hence, a multiple linear regression model was deemed appropriate. The analysis of variance $F$-ratio statistic for the linear fit was $66.38(p<0.001)$. The model explained $42 \%$ of the variance in vancomycin dosing interval $\left(r^{2}=0.42\right)$.

The nomogram developed from these data depicts dosing intervals in hours rounded to standard dosing times (Table 2). If the predicted interval fell between 2 standard dosing intervals, a range is presented. As illustrated in the nomogram, dosing interval increased with increasing age and increasing serum creatinine.

\section{Nomogram Validation With All Dosing Intervals Included in Analysis}

Although none of the nomograms had statistically significantly better performance than the others, the Vancouver General Hospital nomogram and the integrated nomogram had numerically higher validation rates at both sites than the St Paul's Hospital nomogram $(p>0.05)$ (Table 3).

When the integrated nomogram was validated with a 


\begin{abstract}
Table 2. Integrated Nomogram for Determining Vancomycin Dosing Intervals (hours) from Age and Initial Serum Creatinine Level (SCr) to Achieve Trough Levels between 15 and $20 \mathrm{mg} / \mathrm{L}^{*} \dagger$
\end{abstract}

\begin{tabular}{lccccccc} 
& \multicolumn{7}{c}{ Age (years) } \\
\cline { 2 - 8 } $\mathbf{S C r}(\boldsymbol{\mu m o l} / \mathbf{L})$ & $\mathbf{2 0 - 2 9}$ & $\mathbf{3 0 - 3 9}$ & $\mathbf{4 0 - 4 9}$ & $\mathbf{5 0 - 5 9}$ & $\mathbf{6 0 - 6 9}$ & $\mathbf{7 0 - 7 9}$ & $\mathbf{8 0 - 8 9}$ \\
\hline $40-60$ & 8 & 8 & 8 & 8 & $8-12 \ddagger$ & 12 & 12 \\
$61-80$ & 8 & 8 & $8-12 \ddagger$ & 12 & 12 & 12 & $12-18 \neq$ \\
$81-100$ & 12 & 12 & 12 & 12 & $12-18 \neq$ & 18 & 18 \\
$101-120$ & 12 & 12 & $12-18 \neq$ & 18 & 18 & 18 & 18 \\
$121-140$ & 12 & 18 & 18 & 18 & 18 & $18-24 \neq$ & \\
$141-160$ & 18 & 18 & 18 & $18-24 \neq$ & 24 & & \\
$161-180$ & $18-24 \neq$ & 24 & 24 & 24 & & & \\
\hline
\end{tabular}

*With loading dose of $25 \mathrm{mg} / \mathrm{kg}$ and maintenance dose of $15 \mathrm{mg} / \mathrm{kg}$, using actual body weight, up to maximum of $2500 \mathrm{mg}$ per dose.

tShaded boxes indicate patients with unstable and/or reduced renal function, for whom the nomogram may not be as predictive. A clinical pharmacist should be contacted for assistance with dosing and interpretation of levels.

‡Dosing interval as determined by multiple regression analysis fell between standard dosing intervals for vancomycin; recommended interval is therefore presented as a range.

Table 3. Nomogram Validation, with Data Expressed as Proportion of Correctly Predicted Intervals with Each Nomogram in Hospital Test Groups, with and without q18h Dosing

\begin{tabular}{|c|c|c|c|c|c|c|}
\hline \multirow[b]{2}{*}{ Nomogram } & \multicolumn{2}{|c|}{$\begin{array}{l}\text { St Paul's Hospital Test Group } \\
\qquad(n=44)\end{array}$} & \multicolumn{2}{|c|}{$\begin{array}{l}\text { Vancouver General Hospital Test Group } \\
\qquad(n=36)\end{array}$} & \multicolumn{2}{|c|}{$\begin{array}{l}\text { Combined and Expanded } \\
\text { Test Group }(n=106)\end{array}$} \\
\hline & $\begin{array}{l}\text { q18h Dosing* } \\
\text { Included }\end{array}$ & $\begin{array}{l}\text { q18h Dosing } \\
\text { Excluded }\end{array}$ & $\begin{array}{l}\text { q18h Dosing* } \\
\text { Included }\end{array}$ & $\begin{array}{l}\text { q18h Dosing } \\
\text { Excluded }\end{array}$ & $\begin{array}{l}\text { q18h Dosing } \\
\text { Included }\end{array}$ & $\begin{array}{l}\text { q18h Dosing } \\
\text { Excluded }\end{array}$ \\
\hline $\begin{array}{l}\text { St Paul's Hospital } \\
\text { nomogram }\end{array}$ & $23 / 44(52 \%)$ & $23 / 40$ (57\%) & $19 / 36(53 \%)$ & $18 / 28(64 \%)$ & NA & NA \\
\hline $\begin{array}{l}\text { Vancouver General } \\
\text { Hospital nomogram }\end{array}$ & 25/44 (57\%) & 25/39 (64\%) & 25/36 (69\%) & 24/30 (80\%) & NA & NA \\
\hline $\begin{array}{l}\text { Integrated } \\
\text { nomogram }\end{array}$ & $31 / 44(70 \%)$ & $31 / 42(74 \%)$ & $21 / 36(58 \%)$ & 19/27 (70\%) & 59/105 (56\%)† & $57 / 80(71 \%) \dagger$ \\
\hline
\end{tabular}

larger pooled cohort of patients from both sites, it correctly predicted the dosing interval for $56 \%$ of the patients (Table 3 ).

\section{With Exclusion of q18h Dosing}

The q18h dosing interval was the recommended interval for approximately one-third of the entries in the nomogram (Table 2). However, q18h dosing is rarely prescribed in clinical practice. It was suggested that the predictive success of the nomograms might have been adversely affected by the infrequent use of this dosing interval. The validation results were therefore reanalyzed and found to be more consistently predictive when $\mathrm{q} 18 \mathrm{~h}$ dosing was excluded (Table 3). For example, the integrated nomogram correctly predicted the dosing intervals for $71 \%$ of patients in the combined and expanded test group when $\mathrm{q} 18 \mathrm{~h}$ dosing was excluded versus $56 \%$ when q18h dosing was included $(p=0.036)$. The same pattern was seen with the other nomograms but was not statistically significant.

\section{DISCUSSION}

Although vancomycin trough levels between 15 and $20 \mathrm{mg} / \mathrm{L}$ are recommended for the treatment of invasive grampositive infections, validated nomograms to guide high-target dosing are limited. Until now, the validated dosing nomograms used at the 2 study hospitals aimed to achieve vancomycin levels between 5 and $15 \mathrm{mg} / \mathrm{L}$. Thus, the primary aim of this study was to develop and validate initial dosing nomograms that would achieve vancomycin trough levels between 15 and $20 \mathrm{mg} / \mathrm{L}$ in patients with various degrees of renal function. The secondary aim was to compare the predictability of the nomograms, with a view to further development of the most appropriate nomogram. To the authors' knowledge, this is the first high-target vancomycin dosing nomogram to be developed in Canada, and we are aware of only one other published hightarget vancomycin dosing nomogram in North America. ${ }^{12}$

Using multiple linear regression analysis of age and initial serum creatinine, a novel high-target vancomycin dosing 
nomogram was developed for use at the 2 study institutions. Multiple linear regression has been used successfully in previous studies to construct dosing nomograms. ${ }^{8,13,14}$ Furthermore, several other studies have used creatinine clearance in the development of vancomycin dosing nomograms. ${ }^{5,10-12}$

As a more rigorous nomogram, an integrated nomogram was constructed and compared with the institution-specific nomograms. The validation results confirmed that the integrated nomogram could be applied at both sites.

\section{Predictability of Nomograms}

With predictive rates between $52 \%$ and $70 \%$ (including $\mathrm{q} 18 \mathrm{~h}$ dosing), the nomograms were successful at achieving trough levels between 15 and $20 \mathrm{mg} / \mathrm{L}$. The integrated nomogram fared well across both sites, with $70 \%$ and $58 \%$ success rates in the St Paul's Hospital and Vancouver General Hospital test groups, respectively $(p>0.05)$. Even though the integrated nomogram did not perform markedly better than the individual hospital nomograms (Table 3), the integrated nomogram was chosen for implementation and prospective validation because it was constructed from a larger data set derived from both institutions. The narrow validation range $(15-20 \mathrm{mg} / \mathrm{L})$ and the infrequent use of $\mathrm{q} 18 \mathrm{~h}$ dosing in practice may explain the success rates in the various validation groups. It should also be noted that a validated nomogram has the potential to provide a more logical approach to dosing, rather than the subjective and empiric manner in which vancomycin is currently dosed to achieve high-target trough levels.

The high-target vancomycin nomogram recently developed by Kullar and others ${ }^{12}$ yielded validation results similar to ours, specifically $58 \%$ in a prospective test group. However, the nomogram described here offers 2 advantages: first, it can be applied to a broader target patient population; and second, it uses serum creatinine to determine dosing, rather than creatinine clearance, which alleviates the need to calculate clearance and makes bedside use of the nomogram easier. In contrast, the nomogram of Kullar and others ${ }^{12}$ was developed from a larger sample.

In practice, a dosing interval of $\mathrm{q} 18 \mathrm{~h}$ is often regarded as inconvenient and is therefore prescribed less frequently than $\mathrm{q} 8 \mathrm{~h}, \mathrm{q} 12 \mathrm{~h}$, and $\mathrm{q} 24 \mathrm{~h}$ dosing intervals. Thus, it was not surprising that when the nomograms were revalidated with exclusion of the $\mathrm{q} 18 \mathrm{~h}$ interval, success rates were usually higher (Table 3). Nonetheless, although this interval is infrequently used in practice, we did include it in the final nomogram. Although $\mathrm{q} 18 \mathrm{~h}$ dosing leads to variable dosing times from day to day, reliance on $\mathrm{q} 12 \mathrm{~h}$ or $\mathrm{q} 24 \mathrm{~h}$ dosing could result in doses significantly greater or less than $15 \mathrm{mg} / \mathrm{kg}$ to achieve the target level. Including the $\mathrm{q} 18 \mathrm{~h}$ dosing interval in the nomogram is intended to discourage prescribers from using very high or very low doses merely for the purpose of avoiding $\mathrm{q} 18 \mathrm{~h}$ dosing. The use of electronic medication administration records can aid in the determination of administration times, so that nursing staff do not have to determine shifting administration times on an ongoing basis.

\section{Overall Recommendations for Dosing}

To be consistent with recent guidelines, ${ }^{6}$ the authors recommend a loading dose of $25 \mathrm{mg} / \mathrm{kg}$ and a maintenance dose of $15 \mathrm{mg} / \mathrm{kg}$ to a maximum of $2500 \mathrm{mg}$ per dose to achieve high-target levels calculated using actual body weight.

\section{Limitations}

The limitations of this study include its retrospective design (which may have introduced unrecognized biases) and the assumption that all patients had similar pharmacokinetic parameters for vancomycin. The study did not exclude burn and intensive care unit patients, who may exhibit unique characteristics. The extent of vancomycin accumulation after achievement of the high-target level, in addition to adverse effects secondary to high-target dosing, needs to be evaluated. Furthermore, St Paul's Hospital has a unique population, with a high proportion of injection drug users. Because this nomogram was developed using local patient data, its predictability in other populations is unknown. The majority of patients included in this study were clustered in the middle of the nomogram (Figure 1), making predictions at the extremes of age and initial serum creatinine less reliable.

\section{Future Studies}

The integrated nomogram has now been implemented at both of the study hospitals and is being further validated in a prospective patient population. The potential for nephrotoxicity caused by high-target vancomycin dosing is also under investigation.

\section{CONCLUSIONS}

A novel vancomycin dosing nomogram based on age and serum creatinine has been developed and retrospectively validated at 2 Canadian teaching hospitals. This integrated nomogram will assist clinicians in selecting appropriate initial vancomycin regimens to achieve high target levels of $15-20 \mathrm{mg} / \mathrm{L}$, which is expected to optimize patient outcomes. The nomogram has been implemented and a prospective evaluation is under way. Other institutions may wish to validate this nomogram in their particular populations or use the template suggested by this study as a guide in developing nomograms specific to their patient populations.

\section{References}

1. Ackerman BH, Vannier AM, Eudy EB. Analysis of vancomycin time-kills studies with Staphylococcus species by using a curve stripping program to describe the relationship between concentration and pharmacodynamic response. Antimicrob Agents Chemother 1992;36(8):1766-1769. 
2. Lowdin E, Odenholt I, Cars O. In vitro studies of pharmacodynamic properties of vancomycin against Staphylococcus aureus and Staphylococcus epidermidis. Antimicrob Agents Chemother 1998;42(10):2739-2744.

3. Larsson AJ, Walker KJ, Raddatz JK, et al. The concentration-independent effect of monoexponential and biexponential decay in vancomycin concentrations on the killing of Staphylococcus aureus under aerobic and anaerobic conditions. J Antimicrob Chemother 1996;38(4):589-597.

4. Marra F, Cairns B, Jewesson P. Vancomycin serum concentration monitoring. The middle ground is best. Clin Drug Invest 1996;2:106-116.

5. Thomson AH, Staatz CE, Tobin CM, Gall M, Lovering AM. Development and evaluation of vancomycin dosage guidelines designed to achieve new target concentrations. J Antimicrob Chemother 2009;63(5):10501057.

6. Rybak M, Lomaestro B, Rotschafer JC, Moellering R Jr, Craig W, Billeter $\mathrm{M}$, et al. Therapeutic monitoring of vancomycin in adult patients: a consensus review of the American Society of Health-System Pharmacists, the Infectious Diseases Society of America, and the Society of Infectious Diseases Pharmacists. Am J Health Syst Pharm 2009;66(1):82-98. Erratum in: Am J Health Syst Pharm 2009;66(10):887.

7. Rybak MJ. The pharmacokinetic and pharmacodynamic properties of vancomycin. Clin Infect Dis 2006;42 Suppl 1:S35-S39.

8. Prins JM, Weverling GJ, de Blok K, van Ketel RJ, Speelman P. Validation and nephrotoxicity of a simplified once-daily aminoglycoside dosing schedule and guidelines for monitoring therapy. Antimicrob Agents Chemother 1996;40(11):2494-2499.

9. Moise-Broder PA, Sakoulas G, Eliopoulos GM, Schentag JJ, Forrest A, Moellering RC Jr. Accessory gene regulator group II polymorphism in methicillin-resistant Staphylococcus aureus is predictive of failure of vancomycin therapy. Clin Infect Dis 2004;38(12):1700-1705.

10. Matzke GR, McGory RW, Halstenson CE, Keane WF. Pharmacokinetics of vancomycin in patients with various degrees of renal function. Antimicrob Agents Chemother 1984;25(4):433-437.

11. Moellering RC Jr, Krogstad DJ, Greenblatt DJ. Vancomycin therapy in patients with impaired renal function: a nomogram for dosage. Ann Intern Med 1981;94(3):343-346.

12. Kullar R, Leonard SN, Davis SL, Delgado G Jr, Pogue JM, Wahby KA, et al. Validation of the effectiveness of a vancomycin nomogram in achieving target trough concentrations of $15-20 \mathrm{mg} / \mathrm{L}$ suggested by the vancomycin consensus guidelines. Pharmacotherapy 2011;31(5):441-448.

13. Bauman JL, DiDomenico RJ, Viana M, Fitch M. A method of determining the dose of digoxin for heart failure in the modern era. Arch Intern Med 2006;166(22):2539-2545.
14. Perry PJ, Bever KA, Arndt S, Combs MD. Relationship between patient variables and plasma clozapine concentrations: a dosing nomogram. Biol Psychiatry 1998;44(8):733-738.

Rosanne Thalakada, BSC, BSC(Pharm), ACPR, is a Clinical Pharmacist Pharmaceutical Sciences, Vancouver General Hospital, Vancouver, British Columbia.

Michael Legal, PharmD, ACPR, is a Clinical Pharmacy Specialist (Internal Medicine), Providence Health Care, St Paul's Hospital, and a Clinical Assistant Professor, Faculty of Pharmaceutical Sciences, The University of British Columbia, Vancouver, British Columbia.

Tim T Y Lau, PharmD, ACPR, FCSHP, is a Pharmacotherapeutic Specialist in Infectious Diseases, Pharmaceutical Sciences, Vancouver General Hospital, and Clinical Associate Professor, Faculty of Pharmaceutical Sciences, and Associate Member, Division of Infectious Diseases, Faculty of Medicine, The University of British Columbia, Vancouver, British Columbia.

Tiffany Luey, BSC(Pharm), ACPR, is a Clinical Pharmacist, Providence Health Care, St Paul's Hospital, Vancouver, British Columbia.

Josh Batterink, BSC(Pharm), ACPR, is a Clinical Pharmacist, Providence Health Care, St Paul's Hospital, Vancouver, British Columbia.

Mary H H Ensom, BS(Pharm), PharmD, FASHP, FCCP, FCSHP, FCAHS, is Professor and Director, Doctor of Pharmacy Program, Faculty of Pharmaceutical Sciences, and Distinguished University Scholar, The University of British Columbia, and a Clinical Pharmacy Specialist, Children's and Women's Health Centre of British Columbia, Vancouver British Columbia. She is also the Editor of the CJHP.

Address correspondence to:

Dr Michael Legal

Providence Health Care

St Paul's Hospital

1081 Burrard Street

Vancouver BC V6Z 1Y6

e-mail: mlegal@providencehealth.bc.ca

\title{
L Canadian Society of Hospital Pharmacists Société canadienne des pharmaciens d'hôpitaux
}

\author{
Membership Year 2012/2013 (July 1, 2012 - June 30, 2013)
}

Are you a current member of the Canadian Society of Hospital Pharmacists?

CSHP has celebrated 65 years of inspiration and leadership among a rapidly growing network of over 3000 pharmacy colleagues. As a member of CSHP, you will have access to resources and opportunities that will enhance your career and help impact the direction of healthcare in Canada. Your participation in CSHP 2015, an initiative challenging all pharmacists to improve patient medication outcomes and safety through advancing pharmacy practice excellence by the year 2015 , is a prime example.

For more information about CSHP, please visit us at www.cshp.ca. We invite you to reap the benefits of an affordable membership with CSHP.

Membership Enquiries: Please contact Membership Services

Bus.: (613) 736-9733 Ext. 222 Fax: (613) 736-5660Ｅmail: membershipservices@cshp.ca 